\title{
The Design Of Renewable And Interactive E-Book Template For E-Learning Environments
}

\author{
Nuh Hatipoglu, Trakya University, Turkey \\ Nilgun Tosun, Trakya University, Turkey
}

\begin{abstract}
In this study, it is aimed to minimize the labor and time spent during the updating of e-content and re-uploading them into learning management systems, which is one of the present e-learning problems. For this purpose, a new e-book template has been designed. Transferring content into e-book consists of two important steps. Firstly, the contents prepared in MS Word program are transformed into XML. Later, the contents transformed into XML are read by e-book template. EBONI design principles have been highly obeyed during the design of the template. Some of the EBONI design principles used in the e-book template are book cover, contents, short page contents, legible writing format, multimedia and interactive items that may activate users. Thanks to these, an e-learning environment that is visually rich, easy to understand and follow with flexible contents has been attempted to create.
\end{abstract}

Keywords: e-learning, e-book, XML

\section{Introduction}


E - Learning is a method which provides the opportunity of education and teaching to millions of people in various areas nowadays. The environments used while applying e-learning method are preferred today due to their advantages against traditional teaching-learning environments. Some of these advantages are; being independent of time and place, opportunity of individual learning, low cost in long term, easy access to course contents, presenting many different course material at the same time.

Using various course materials plays a vital role in increasing the course motivations and willingness of learning of learners. Plentitude of visual, audial, and live materials is an undeniable factor in the retention of knowledge and skills.

In the e-learning environments knowledge in various formats such as doc, docx, flw, swf are presented with different tools to the learners. One of these tools is e-books. Despite the advantages of easiness of access and use, updating of e-books is one of the major problems of this field. E-books prepared and presented for use in electronic environments have a static structure whose pages have been filled with fixed data. However, what is needed is that the content of the e-book may be changed easily by the instructor when he wants. Doing this without needing professional software knowledge, flexible and dynamic structure of the e-book template is highly crucial.

The purpose of this study is to develop an e-book template which can be prepared and updated easily. Thanks to this, it is targeted to decrease the labor force of both instructors and content developers, and to save time and labor.

\section{E-Learning}

Recent technological developments and the e-transformation band that the world heads for have started to add "e" letter to the head of many concepts in our lives. The most important factors in this point are that the facilities presented by computer and internet technologies have increased and their usages have become common. Thanks to these, the necessities in the areas of education, health, banking, entertainment, and tourism have begun to be supplied faster, safer and easier. In the ongoing process, "e" letter has been added to the head of all of 
these words (Keser, 2005). E-state, e-trade, e-banking, and e-signature are the major new concepts that we have been used to hear today.

In addition to many other processes, education methods change day by day with technological developments, too. E-learning is shortly; conducting learning activities in electronic environments or transferring knowledge and skills via electronic technologies (Gülbahar, 2009). E-learning can be seen as a development that will affect traditional education and teaching perception and may change the quality of education process. Not only the style of teaching but also the teaching materials have changed with e-learning. Books that are the most well-known teaching-learning tools are subject to most radical change. Books have turned into a format where they can be read on the screen, be heard, and interacted with the support of the multimedia technologies nowadays.

\section{E-Books}

Books have been the most crucial tool of knowledge transfer in the distribution of information, and academic discussions since the invention of the printing machine. Both electronic publishing and universal distribution and access through internet have developed, and e-book has been an evolution for the transfer of knowledge (Chen, 2002).

There exist many definitions about the concept of e-book in the field literature. Diaz defined electronic book as an interactive information system which is organized conceptually like a printed book in order to provide its users to use suitable pages. Serious achievements and progresses have been observed in the design of e-books in the recent years. This definition can be used in many various areas such as digital press, multimedia applications, internet technology, interface design users (Gregorio-Rodrigez et al. 2002).

As well as containing all the features of its printed version, e-book is a media format that contains audio, image, film, with interactive multimedia connections which can be read/watched in computers and specially designed hand tools. Electronic books show opportunities of discovery to find new ways in the interaction with information. Electronic books consist of many benefi- 
cial learning activities including reading, problem solving, and self-assessment (De Jong, 2003).

According to a narrow description e-book; "is a digital object designed to be listened from the tool providing speech or to be read from a reading tool." An e-book is usually a combination of a few digital objects and documents. These are packed and formed to be shown on computers or hand tools, or to be read the writing objects by an application producing speech. An e-book is a numerical publication which includes content files, style papers, information, numeric rights, circulation and other components. Content is composed of text documents, numeric pictures, graphics,amd multimedia applications. Style papers include information about typography, and page order, and how to develop the content. Other files put the content of the book into order (Hillesund, 2001).

According to Rao(2004); e-book is a word used to define content, format, reader software, and reading device at the same time. Here the content means components having good features; format means document or file format; e-book reader represents the software which enables reading the documents in different formats. E-book reading tool has the meaning of suitable portable software for e-book reading. Electronic books which will bring many benefits to readers, writers, and publishers have different definitions in different places. E-book simply fast books which provide access to the content of any book in electronic environments to the readers (Chen, 2002). It may be defined technically as electronic files alike with printed books which can be read with computers and other e-book reading devices. E-books are new numeric book forms which are designed to be read with computers or portable e-book readers, and which provide new facilities in addition to having all the features of printed books but not being printed on papers. E-book consists of hardware and software. Assessing in this perspective, e-books associate with a specially designed portable hardware combination (Morgan, 1999, Rukancı and Anameriç, 2003).

Electronic books can also be defined as presenting readers information in electronic environment with using the infrastructure of classical books or materials suitable with the concept of book. In conceptual sense, e-books may be defined as taking the features of printed books ap- 
plicable with the nature of electronic environment and dealing with the problems and limitations of using printed books. Main features of e-books can be stated as its being dynamic, and interactive, and its being applied in short term in various formats. However, we cannot say that each publication and reader type is appropriate for transition from printed publishing to electronic environment. Therefore; reading process and understanding of reader about what he reads play a vital role in determining to what degree the publication is suitable for its transformation in electronic environment (Landoni and Gibb, 2000).

\section{Types of E-Book}

Allison (2003) divides the electronic course books into three main categories; "simple, compound" and "advanced". Each group has its own sub-categories (Şensoy Öngöz and Baki, 2010):

1. Simple E-Books: Gutenberg project conducted by Michael Hart can be regarded as the starting point of only text type e-course books. The purpose of this project which was started in 1971 was to form a library of a 10.000 e-book capacity in Illinois University that public can use free. Later, the user number of the library increased, and this virtual environment became a source that serves people all over the world. In the library where it serves at http://www.promo.net/pg/ address, it is possible to reach thousands of texts of e-books via FTP including the world classics whose copyright rights are over.

2. Compound E-Books: Compound (complex) e-course books have emerged recently as a result of the development in computer technologies. It is composed of many components addressing different senses such as sound, picture, video, graphic, and animation. One of the important features that set it apart from other types is that learners become members with paying a certain fee in order to reach the environment. E-books of this type are mostly preferred by commercial publishers.

3. Advanced E-Books: they are electronic books which are interactive, graphical, or which can make search in it. Different from the other two types, this type takes the reader almost in it. Interaction has become prominent. 


\section{E-Book Design Principles}

A guide material named "The Design Principles of Electronic Books" that explains the components of hardware and software an e-book should have was published by EBONI in 2002. The principles necessary for a learning material to be regarded as an e-book, and indicators about these principles are presented elaborately in this source.(Wilson,and Landoni, 2002). In this study, EBONI design principles will be complied with for an e-book considered to be designed. The design features determined by EBONI necessary for an e-book and its indicators have been stated below:

- Book cover

- The contents

- The index

- The search tool

- To be a nook on its own

- Short page contents

- Multi connections' making it easy to surf in the book and among the sources.

- Making composition design carefully

- Content clues

- Giving introductory information about the chapters of the book

- Legible writing format

- Using Harmonious and not tiring for eye colors

- Dividing the texts into short parts

- Using the elements other than writing carefully

It can be said that e-books having these features will make readers happier and thus; they will bring success quality with them. EBONI standards are highly crucial for e-book designers in our day. Especially designing e-course books according to certain principles will fit flexibility of e-learning, and transferability of the information (Şensoy Öngöz and Baki, 2010). 


\section{Method}

In this study, dealing with the problems in updating e-course content and re-uploading it to the learning management system has been emphasized. Accordingly, an e-book template has been designed.

The design procedure of an e-book template consists of mainly two parts. The first part is transforming the course content prepared in MS Word program into XML; and the second part is reading of the course content transformed into XML by e-book template.

\section{Transforming the Course Content into XML}

Making some markings are necessary when preparing course contents in MS Word program. But these markings are not a different procedure from adding heading when preparing the content. In Figure1 the content prepared by a lecturer in MS Word environment is shown.

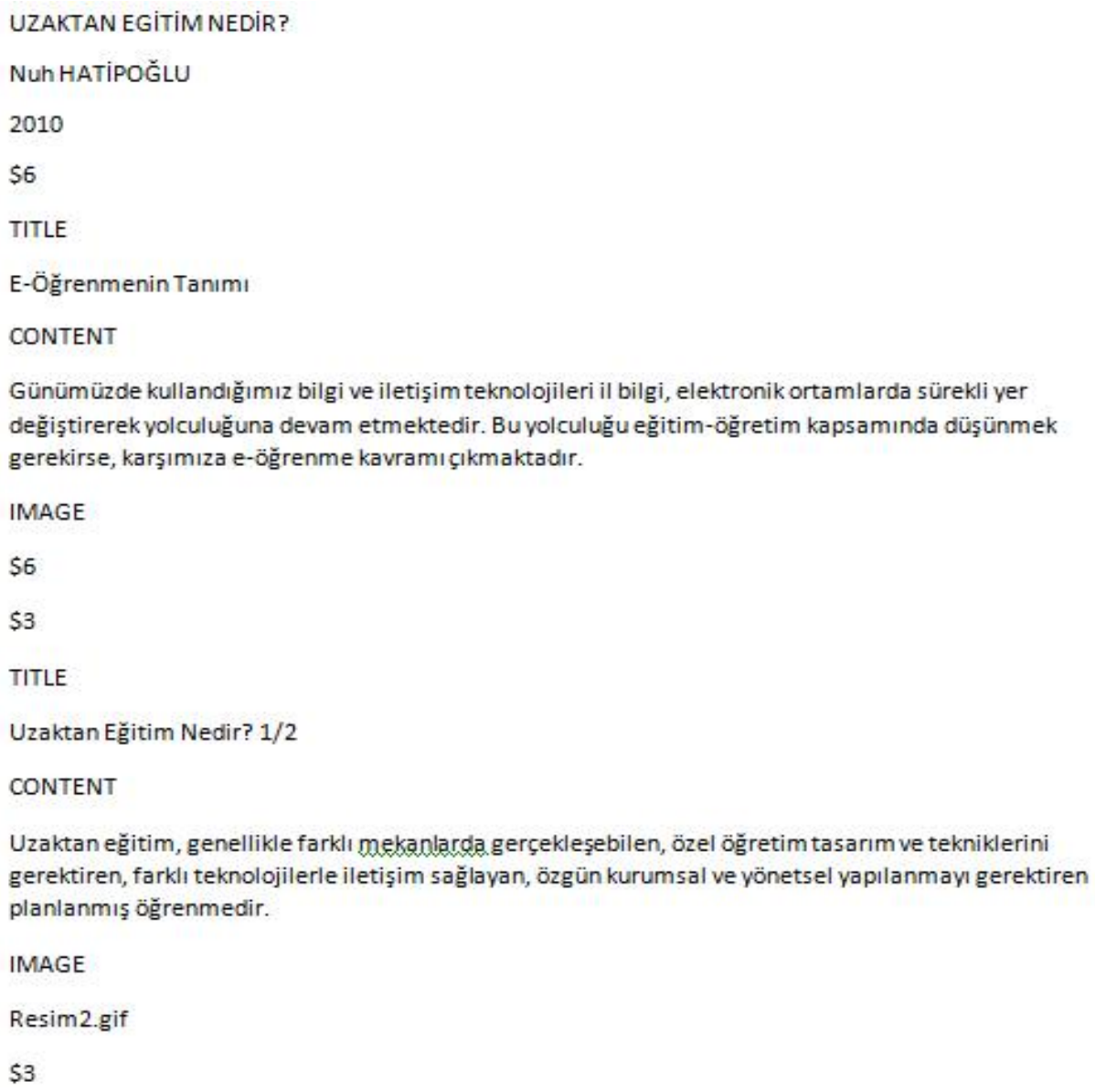

Figure 1The course content prepared by a lecturer 
In the first three lines; the name of the book, the name of the person who prepared the book, and the preparation year of the book should be placed respectively. The following \$ markings states the order of the contents in e-book. The line under TITLE is the page heading that will be shown in e-book. The line after the CONTENT is the text in e-book. IMAGE is the information of the name and types of the picture, animation, and videos in e-book.

XML Translator program the interface of which is demonstrated in Figure 2 has been developed with using NET 3.5 Framework and C\# language. The course note prepared with MS Word is uploaded to the program thanks to the button in source file section. With the parse file button the transformation from MS Word to XML is completed. The documents that come out of the program are saved in C: $\ \backslash$ Flash folder with the name of xmlPages.xml.

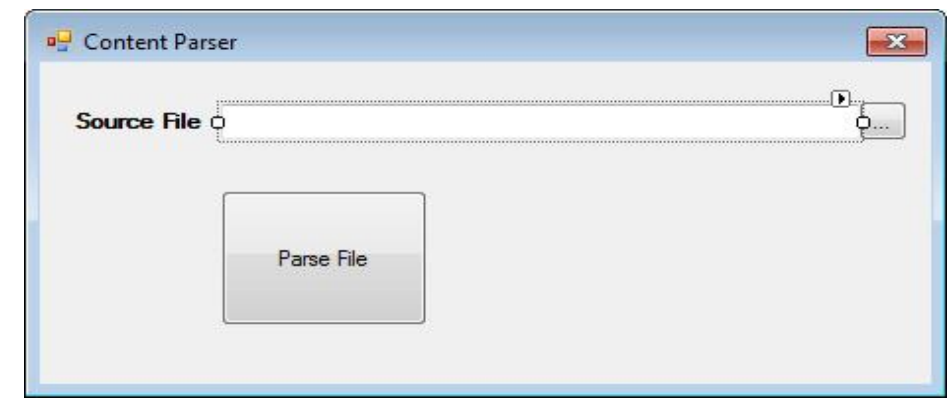

Figure 2 XML Translator Program Interface.

In figure 3, XML output worked in XML Translator Program is placed. Each page button shows the page of the e-book. Page number shows the page number, page type shows the design of the page. Title states the heading of the e-book, and content is the content of the text. Image is the XML element where the pictures, animations, video, and other visual materials that will be in e-book page. Content or image may not be in XML tree according to the page type. 


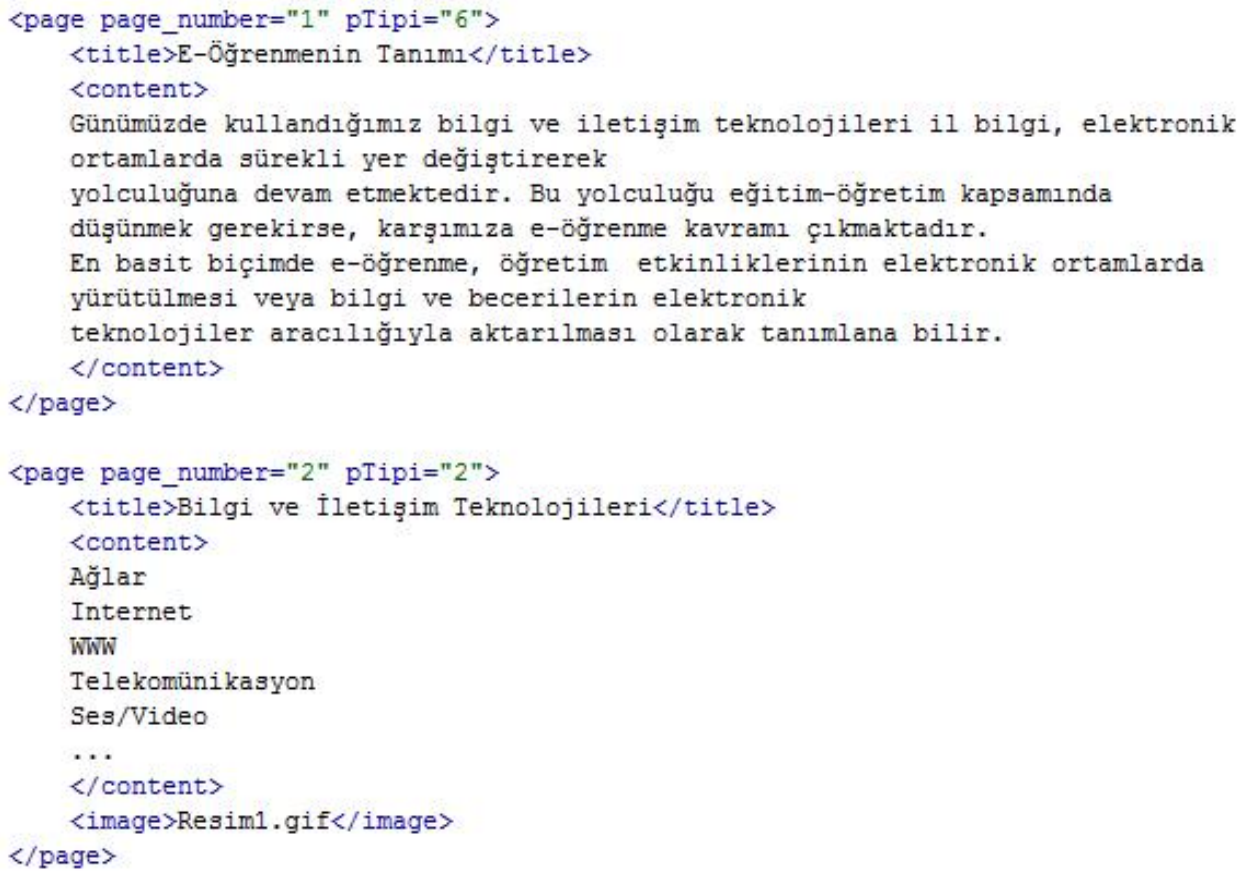

Figure 3 XML Translator Program Output.

\section{Creating an E-Book Template}

Using Adobe Flash CS3 program, E-book template has been developed in ActionScript 3.0 language. The developed E-book template has two has 6 different pages layout. The page layouts are shown in Figure 4.

In Figure 4A, visuals are located on the left of the page and texts are located on the right of the page. Meanwhile in figure $4 \mathrm{~B}$, the texts are located on the left of the page and the visuals are on the right. According to the layout in the Figure 4C, figures are located at the top of the page and texts are below them. The layout in Figure 4D is just opposite of the one in the Figure 4C. According to Figure 4E type of layout, there is no text but the title. There are only visuals on the page. In Figure 4F, while there included no visuals, there are only textual expressions. While preparing notes in MS Word, numbering the $\$$ pointers from 1 to 6 , the desired page layout is chosen from the ones included in Figure D. Page layouts in XML file P type attribute gets a figure between 1 and 6 . 

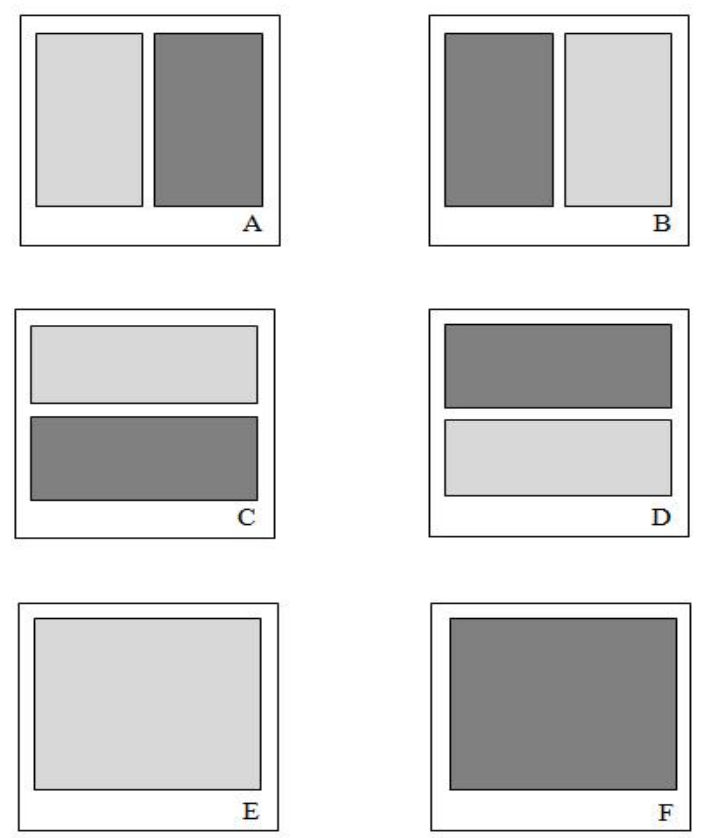

Figure 4 Example of a figure caption (figure caption).

In Figure 5, it is illustrated the e-book cover, of which the template design has been done. On the cover of the e-book, title of the book, author's name, year of preparation and button to enter the book appear. 


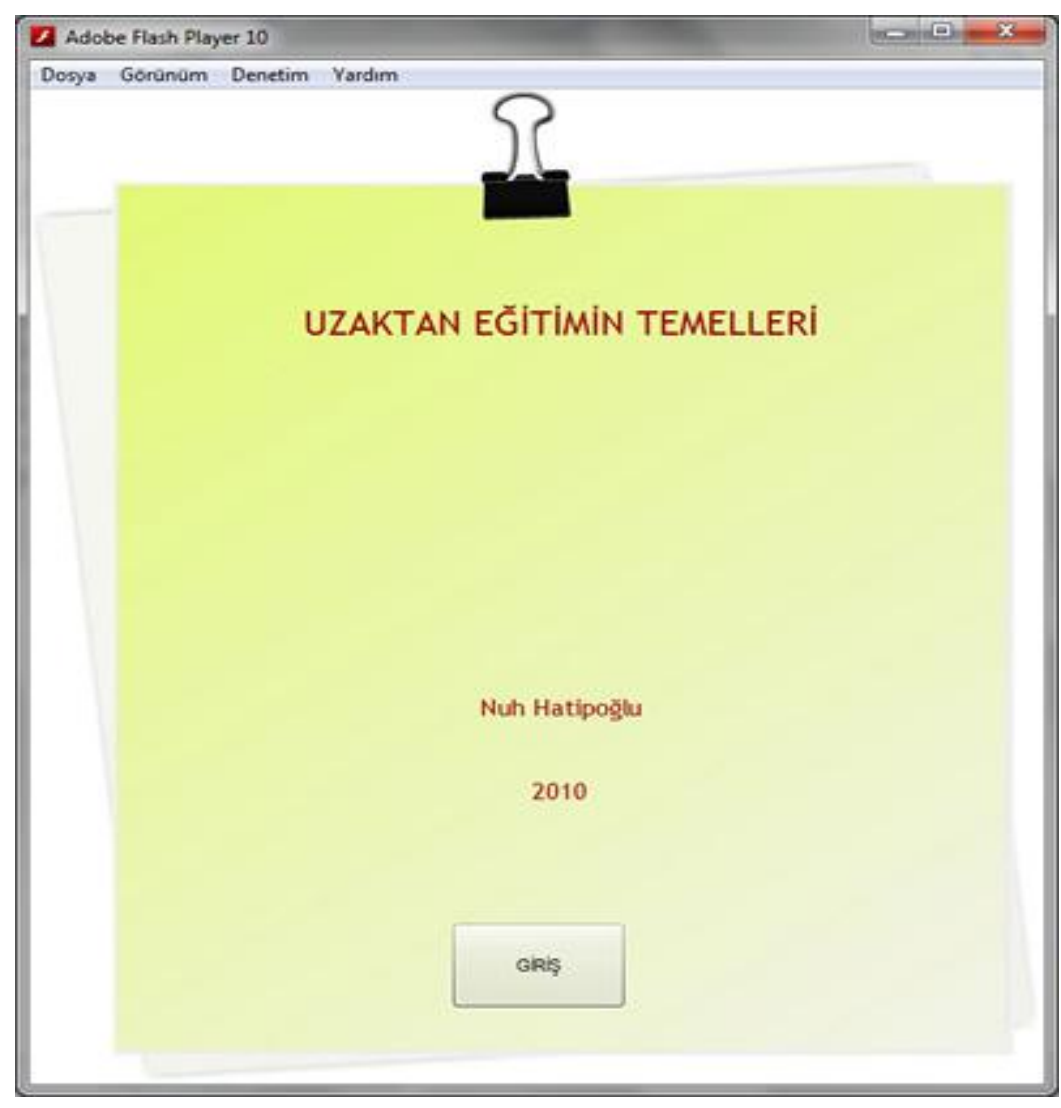

Figure 5 E-book cover.

In figure 6, there is an example of pages other than cover page. All the pages of the e-book other than the cover have the buttons of "next", "previous", "content" and "go". Also, page number appears on all the pages. While the "next" button make it possible to go the following pages one by one, by clicking "previous" button you can go back to previous pages one by one. The "Go" button is used to go directly to the specified page. The button "Content" leads you to see subject titles included in the E-book. It is possible have direct access to the page of the subject by clicking the preferred subject title. Page number indicator in the low right corner of the page has two parts. Right part of the indicator shows the total number of pages whereas left part shows the number of present page.

While designing the pages other than the cover, it has been elaborated on not using a scrollbar so that student can see the whole page on screen at once. Also according to EBONI principles, it is suggested to take texts short in E-books. Thus, it is easier to read the texts. 


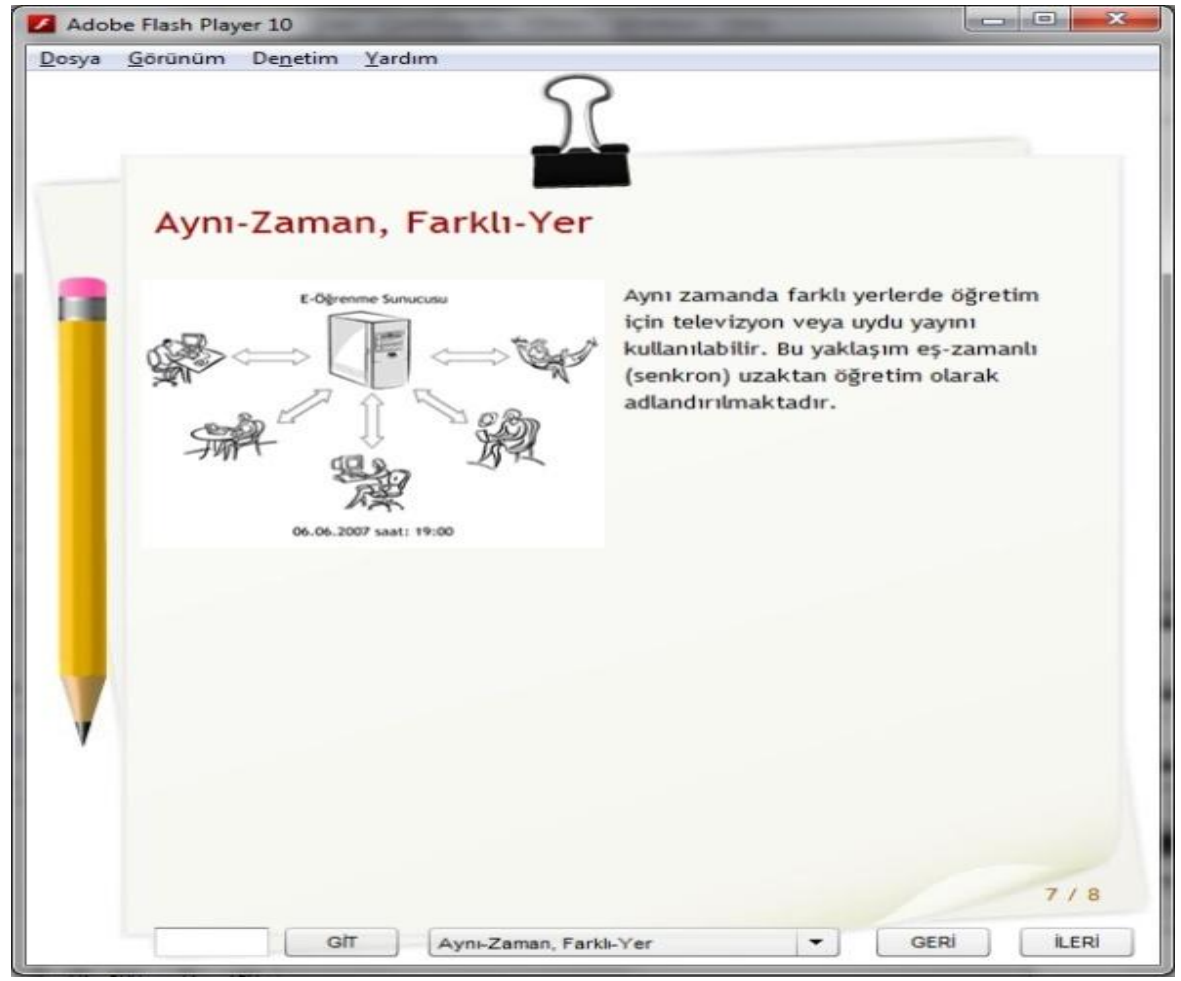

Figure 6 E-Book templates file structure.

E-Book template works in the file structure shown in Figure 7. If the E-book will work on a web page it is used as a HTML file and when it will work locally it is used as a SWF file.
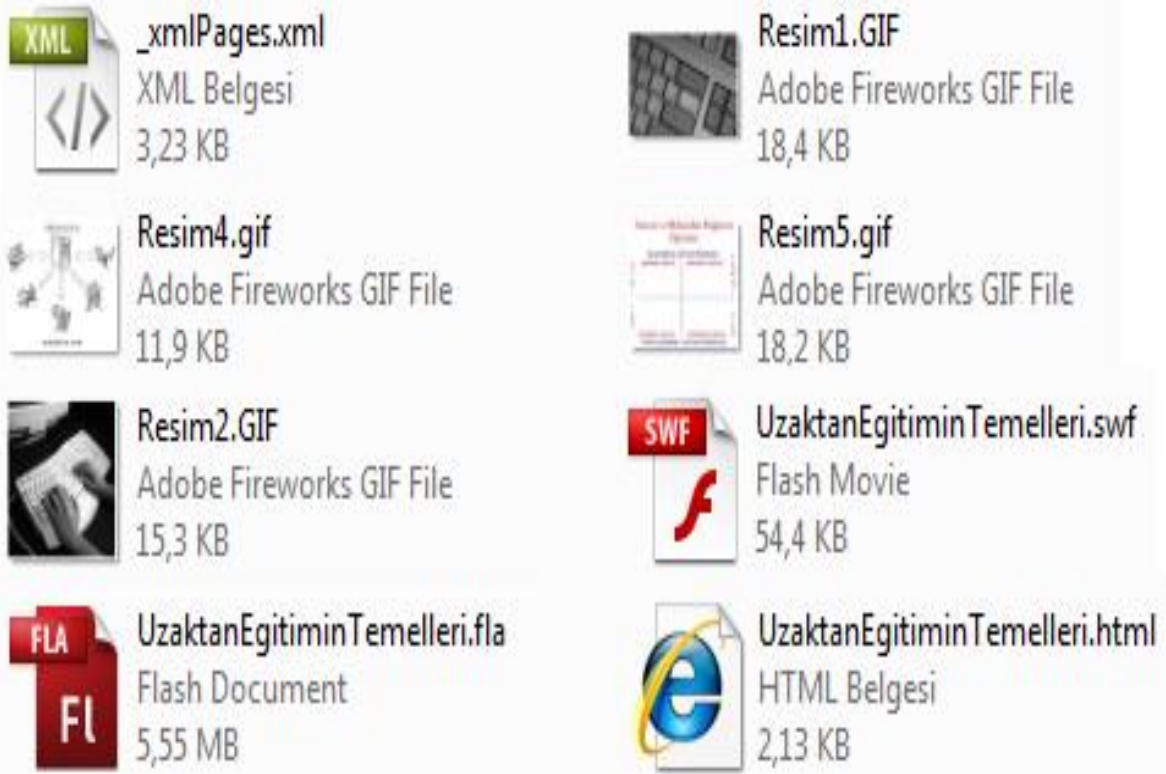

Figure 7 Example of a figure caption (figure caption). 


\section{Conclusion}

Updating the content of the course and uploading it to the learning management system afterward is one of the most important problem encountered by the ones working in the e-learning field. Updating especially already existing content and reloading processes lead to significant amount of waste of time for both the course instructor and the mangers of the learning management system. Starting from this necessity, it is decided to find a solution which will be able to work in the learning management system and eliminate the waste of performance and time. For this purpose, an e-book template is developed for the course contents prepared in numeral environment by using downloading data technique from XML.

Developed e-book template significantly increases the performance of packing, preparation and update of the e-learning content. Because, thanks to this template the texts needed to be edited and changed are not repacked, these processes are carried out on XML. Also, it is thought that the template will significantly decrease work load by providing ease during the preparation phase of content as well.

Before and during developing the e-book template, a long review of literature has been done using many resources about the subject. It is attempted create a reference source for those who are interested in the subject by making a collection of information acquired from the resources.

Many researches and activities can be carried out as a follow-up of this study. For example, this template can be adapted to work on mobile learning media. As it is known, mobile learning is currently one of the popular alternatives for learning and teaching. In this kind of learning media, the problem is the limitation of using visual materials. E-book template can be adapted to mobile media by lessening the visual design materials and increasing text content.

Also this template can be developed to support SCORM (Sharable Content Object Reference Model) in order to work more effectively in LMS(Learning Management System)’s. 
Another work to do after this study is to make instructors, content developer and mangers of teaching management systems use e-book template working in the field of e-learning. With the feedbacks acquired after this process, practicality, performance of time and labor of the template should be clarified. 


\section{References}

Keser, H. (2005). Insan bilgisayar etkileşimi ve să̆lı̆̆a etkisi, Ankara: Nobel Yayinlari.

Gülbahar,Y. (2009). E-ögrrenme, Ankara: Pegem Akademi.

Chen, Y. (2002). Application and development of electronicbooks in an e-Gutenberg Age, Online Information Review, 27, 1-16.

Gregorio-Rodríguez, C., Llana-Díaz, L.F., Pareja-Flores, L.F., Martínez-Unanue, R., Velázquez-Iturbide, J.Á., Palao-Gostanza, P. (2002). A system to generate electronic books on programming exercises, The Electronic Library, 20, 147-164.

De Jong, M.T., Bus, A.G. (2003). How well suited are electronic books to supporting literacy?, Journal of Early Childhood Literacy, 3, 147-164.

Hillesund, T, (2001, 1 October), Will e-books change the world. First Monday, URL(last checked 10 May 2010)

http://firstmonday.org/htbin/cgiwrap/bin/ojs/index.php/fm/rt/printerFriendly/891/800

Rao, S.S, (2004). E-book technologies in education and India's readiness, Electronic Library and Information Systems, 38, 257-267.

Morgan, E. L, (1999). Electronic books and related technologies, Computer in Libraries, 19, 36-39.

Rukancı, F., Anameriç, H, (2003). E-kitap teknolojisi ve kullanımı, Türk Kütüphaneciliği 17, 147-166.

Landoni, M., Gibb, F, (2000). The role of visual rhetoric in the design and production of electronic books: the visual book, Lecturer in the Department of Information Science, 18, 190-201.

Allison, KJ. (2003). Rhetoric and hypermedia in electronic textbooks, Denton University, Texas, USA.

Şensoy Öngöz, S., Baki, A, (2010). E-book usage of graduate students studying educational sciences in Turkiye, Turkish Online Journal of Distance Education-TOJDE, 11, URL (last checked 09 May 2010) http://tojde.anadolu.edu.tr/tojde37/articles/article_13.htm

Wilson, R., Landoni, M., Gibb, F. (2003). Guidelines for designing electronic books, URL (last checked 09 June 2010) http://eprints.cdlr.strath.ac.uk/1903/ 